\title{
Resveratrol inhibits cadmium induced neuronal apoptosis by modulating calcium signalling pathway via regulation of MAPK/ mTOR network
}

\author{
Feng Lin', Yu-Hua Peng1, Qing-He Yang1 and Xiu-Ju Mi² \\ ${ }^{1}$ Department of Neurology, Liaocheng No. 2 People's Hospital, Liaocheng 252000, China; ${ }^{2}$ Department of \\ Neonatology, Liaocheng People's Hospital, Liaocheng 252000, China.
}

\begin{tabular}{|c|c|}
\hline \multicolumn{2}{|l|}{ Article Info } \\
\hline Received: & 15 March 2015 \\
\hline Accepted: & 28 March 2015 \\
\hline Available Online: & 22 April 2015 \\
\hline \multicolumn{2}{|c|}{ DOI: 10.3329/bjp.v10i2.22588 } \\
\hline \multicolumn{2}{|c|}{$\begin{array}{l}\text { Cite this article: } \\
\text { Lin F, Peng YH, Yang QH, Mi XJ. } \\
\text { Resveratrol inhibits cadmium induced } \\
\text { neuronal apoptosis by modulating } \\
\text { calcium signalling pathway via regu- } \\
\text { lation of MAPK/mTOR network. } \\
\text { Bangladesh J Pharmacol. 2015; 10: 366- } \\
76 \text {. }\end{array}$} \\
\hline
\end{tabular}

\section{Article Info}

Available Online:

28 March 2015

22 April 2015

\section{Abstract}

Cadmium, a toxic environmental contaminant, induces oxidative stress leading to various neurodegenerative disorders, where it interferes with homeostasis of intracellular free calcium $\left(\left[\mathrm{Ca}^{2+}\right] \mathrm{i}\right)$, leading to cellular damage and apoptosis. We investigated whether resveratrol, a plant-derived antioxidant could offer protection against cadmium-induced neuroapoptosis. Primary cortical neurons were exposed to cadmium $(10$ or $20 \mu \mathrm{M})$ with/without prior exposure to resveratrol $(5,10$ or $20 \mu \mathrm{M})$ for 12 hours and unexposed cells served as control. Resveratrol caused marked reduction in cadmium-induced neuronal apoptosis and down-regulated caspase-3 expressions. Cadmiuminduced marked elevations in reactive oxygen species, and ([Ca $\left.{ }^{2+}\right]$ i) levels were potentially reduced by resveratrol. Resveratrol effectively regulated the alterations observed in the activation levels of mitogen-activated protein kinases (MAPKs) and proteins of mammalian target of rapamycin (mTOR) pathways. Thus, resveratrol effectively protected the cortical neurons exposed to cadmium by modulating the ([Ca $\left.\left.{ }^{2+}\right] \mathrm{i}\right)$ levels and regulating the MAPK/ mTOR pathways.

\section{Introduction}

Cadmium is an extremely toxic environmental pollutant commonly found in industrial workplaces, released from metal refining, smelting, and burning of fossil fuels and municipal wastes. Cadmium is toxic to many body organs including liver, kidney and brain (Lopez et al., 2006; Prabu et al., 2011; Oliveira et al., 2012; Napolitano et al., 2012; Coccini et al., 2013). Cadmium has high blood-brain barrier permeability and chronic exposure affects nervous system leading to memory deficits, olfactory dysfunction and hypernociception (Pihl and Parkes, 1977; Lukawski et al., 2005; Nishimura et al., 2006; Wright et al., 2006). Increasing evidences indicate cadmium in the etiology of many neurodegenerative diseases (Okuda et al., 1997; Panayi et al., 2002; Jiang et al., 2007; Chen et al., 2011c).
Cadmium induced oxidative stress interferes with proteins, lipids and DNA and alters their functions (Stohs and Bagchi, 1995; Figueiredo-Pereira et al., 1998; Green and Peers, 2002; Kim et al., 2005). Cadmium interacts with the functions of many $\mathrm{Ca}^{2+}$ dependent enzymes as protein kinase $\mathrm{C}$ (PKC) and mitogen-activated protein kinase (MAPK) (Lohmann and Beyersmann, 1993; Beyersmann and Hechtenberg, 1997; Misra et al., 2002). Intracellular calcium homeostasis is pivotal in cellular function, survival and death (Clapham, 2007). Cadmium induced disruption in intracellular free calcium $\left(\left[\mathrm{Ca}^{2+}\right]_{\mathrm{i}}\right)$ homeostasis leads to apoptosis (Lemarie et al., 2004; Liu and Templeton, 2008; Yang et al., 2008; Son et al., 2010; Xie et al., 2010).

$\mathrm{Ca}^{2+}$ mediates numerous physiological responses of neurons (Cheng et al., 2003; Neher and Sakaba, 2008; Surmeier et al., 2010) and disruptions in $\mathrm{Ca}^{2+}$ levels 
disturbs many signalling cascades (Liu and Templeton, 2008). $\mathrm{Ca}^{2+}$ levels are critical for activation of mammalian target of rapamycin (mTOR) (Gulati et al., 2008). mTOR is important for development and survival of neurons. Altered mTOR activity has been observed in neurodegenerative disorders and brain tumors (Ravikumar et al., 2004; Swiech et al., 2008). Chen et al. (2008; $2011 b$, c) demonstrated that MAPK and mTOR pathways are involved in cadmium induced neuronal apoptosis. Thus, targeting these pathways could be a potential strategy in therapy of neurodegenerative disorders and in cadmium-induced toxicities.

Resveratrol (3,5,4'-trihydroxystilbene), a polyphenolic phytoalexin is found in grapes, berries and also in many other plants (Sovak, 2001). Numerous pharmacological properties have been attributed to resveratrol including antioxidant, cardioprotective, and antiproliferative activities (Fremont, 2000; Fulda, 2010; Lin et al., 2013; Cullberg et al 2014; Lephart et al 2014). With this background, we investigated the effect of resveratrol in cadmium-induced neuroapoptosis.

\section{Materials and Methods}

\section{Reagents and chemicals}

Dulbecco's modified eagle's medium (DMEM)-F12 (1:1), 2-aminoethoxydiphenyl borate (2-APB), 2',7'dichloro-dihydrofluorescein diacetate $\left(\mathrm{H}_{2}-\mathrm{DCF}-\mathrm{DA}\right)$, trypsin, penicillin/streptomycin, BAPTA (1,2-bis(oaminophenoxy) ethane-N,N,N',N'-tetraacetic acid) and Poly-D-lysine (PDL), resveratrol were obtained from Sigma-Aldrich (USA). Cadmium chloride (Sigma, USA) was dissolved in sterile double distilled water and the stock solutions (0-20 mM) were prepared. For western blot analysis, following antibodies were used: phosphop38 (Thr180/Tyr182), phospho-Erk1/2 (Thr202/ Tyr204), phospho-mTOR (Ser2448), mTOR, phosphoAkt (Ser473), phospho-S6K1 (Thr389), 4E-BP1, phosphoS6(Ser235/236), S6, caspase-3, cleaved caspase-3 (Asp175), PTEN (Cell Signaling Technology, USA), JNK, phospho-JNK (Thr183/Tyr185), c-Jun, phospho-cJun (Ser63), Erk1/2, p38, Akt, S6K1 (Santa Cruz Biotechnology, USA), $\beta$-tubulin (Sigma-Aldrich, USA), goat anti-rabbit IgG horseradish peroxidase (HRP), goat anti-mouse IgG-HRP, and rabbit anti-goat IgG-HRP (Pierce, Rockford, IL, USA). NEUROBASAL ${ }^{\mathrm{TM}}$ medium, B27 supplement and fluo-4/AM were procured from Invitrogen (USA). The other chemicals that were used in this study were obtained from Sigma Aldrich (USA), unless otherwise mentioned.

\section{Cell isolation and culture}

Primary rat cerebral cortical neurons were cultured from fetal Sprague-Dawley rats (18-19 days of gestation) as described formerly by Yan et al. (2012). The isolated cells were seeded at a density of $2 \times 10^{4}$ cells/well in 96-well plates which were coated with 100 $\mathrm{mg} / \mathrm{L}$ poly-L-lysine in NEUROBASALTM medium supplemented with L-glutamine $(1 \mathrm{mM})$, penicillin (100 $\mathrm{U} / \mathrm{mL})$, streptomycin $(100 \mathrm{U} / \mathrm{mL})$ and B27 supplement at $2 \%$ and were cultured in a humid incubator at $37^{\circ} \mathrm{C}$ in $5 \% \mathrm{CO}_{2}$. The cells were used for analysis after 7 days of culture. Fetal Sprague-Dawley rats were obtained from Laboratory Animal Center in Yangzhou University (Yangzhou, China). This research study was performed with strict adherence to the recommendations specified in the Guide for the Care and Use of Laboratory Animals of the National Research Council and was approved by the Institutional ethical committee.

Assessment of cell viability and morphological changes

\section{DAPI staining for morphology analysis}

The neuronal cells were seeded at a density of $5 \times 10^{5}$ cells/well in a 6-well plate comprising a PDL coated glass coverslip per well and cells were cultured for 24 hours, following which cells were then treated with various concentrations of resveratrol $(5,10$ and $20 \mu \mathrm{M})$ for 12 hours. After treatment with resveratrol, cells were incubated with/without cadmium (10 and $20 \mu \mathrm{M})$ for 12 hours and observed for morphological changes (fragmented and condensed nuclei) using DAPI staining as described by Chen et al. (2008) and cells were observed with fluorescence microscope (Nikon 80i, Japan)

\section{Cell viability assay}

Primary neurons exposed to resveratrol and/or cadmium was washed twice with phosphate buffered saline and were analysed for cell viability. Apoptosis was determined by LIVE/DEAD viability (LIVE/ DEAD cell viability kit, Invitrogen) assay. The assay determines plasma membrane integrity to assess the viability of cells. Treated or untreated cells were stained with $5 \mu \mathrm{mol} / \mathrm{L}$ ethidium homodimer and $5 \mu \mathrm{mol} / \mathrm{L}$ calcein-AM and incubated at $37^{\circ} \mathrm{C}$ for $30 \mathrm{~min}$ following which the cells were analyzed for viability under a Nikon labophot-2 fluorescence microscope. The assay relies on the intracellular esterase activity within living cells, through which the calcein-AM, a cell permeable fluorogenic esterase substrate, hydrolyzes to the green fluorescent product calcein. Live cells will retain calcein -AM, and produce a green fluorescence. Further, ethidium homodimer enters damaged membranes of the dead cells and binds to nucleic acids thereby producing a red fluorescence.

\section{Analysis of intracellular free $\mathrm{Ca}^{2+}$ concentration $\left(\left[\mathrm{Ca}^{2+}\right]_{i}\right)$}

For $\left[\mathrm{Ca}^{2+}\right]_{\mathrm{i}}$ detection, cortical neurons were cultured in 6 -well plates and incubated with BAPTA-AM (10 mM), or 2 -APB $(50 \mathrm{mM})$ for $30 \mathrm{~min}$ and cells were subjected to various concentrations of resveratrol and/or Cd for another 12 hours. The harvested cells were incubated with Fluo-4/AM (5 mmol/L final concentration) for 30 
min at $37^{\circ} \mathrm{C}$ in dark and were washed with PBS, analyzed for fluorescence using fluo-4/AM as an intracellular free $\mathrm{Ca}^{2+}$ fluorescent probe to analyse $\left[\mathrm{Ca}^{2+}\right]_{\mathrm{i}}$ in cadmium exposed cerebral cortical neurons. $\left[\mathrm{Ca}^{2+}\right]_{\mathrm{i}}$ levels signified by intensity of fluorescence was recorded (494 $\mathrm{nm}$ and $516 \mathrm{~nm}$ ) and data was analyzed by Cell Quest program (Becton Dickinson).

\section{Assessment of ROS generation}

Generation of intracellular ROS was measured using $2^{\prime}, 7^{\prime}$-dichlorofluorescein diacetate (DCFH-DA) staining by flow cytometry where DCFH-DA is an nonfluorescent compound which gets converted to DCF enzymatically in presence of ROS. After exposure of BAPTA-AM (10 mM) for $30 \mathrm{~min}$, the cells were treated with resveratrol followed by cadmium $(10$ and $20 \mu \mathrm{M})$ for 12 hours. Cells were further incubated with DCFHDA $(10 \mu \mathrm{M})$ for $30 \mathrm{~min}$ at $37^{\circ} \mathrm{C}$ in dark and were washed twice with PBS and intensity of fluorescence was measured (Lu et al., 2004).

\section{Western blot analysis}

After treatment with cadmium and/or resveratrol, the cells were treated and washed with cold PBS and prior to cadmium or resveratrol exposure, they were incubated with/without BAPTA-AM as stated before. The cells were lysed in RIPA buffer ( $50 \mathrm{mM}$ tris, $\mathrm{pH} 7.2$; $1 \mathrm{mM} \mathrm{Na} 3 \mathrm{VO}_{4} ; 1 \%$ sodium deoxycholate; $0.1 \%$ SDS; $1 \%$ Triton-X 100; $150 \mathrm{mM} \mathrm{NaCl} ; 10 \mathrm{mM} \mathrm{NaF} ; 1: 1000$ protease inhibitor cocktail) and the lysate was further sonicated for $10 \mathrm{sec}$; centrifuged at 14,000 rpm for 10 min at $4^{\circ} \mathrm{C}$. Using bovine serum albumin as standard, the protein concentration was determined where equivalent amounts of proteins were separated on SDSpolyacrylamide gel (7.5-12\%) and blotted to polyvinylidene difluoride membranes (Millipore, USA). Membranes were incubated with blocking solution (phosphate buffered saline containing $0.05 \%$ Tween 20 and $5 \%$ nonfat dry milk) to block non-specific binding and were incubated with primary antibodies followed by equivalent horseradish peroxidise conjugated secondary antibodies. Positive bands were visualized using enhanced chemiluminescence solution (GE Healthcare). The band signals of other proteins were normalized to those of $\beta$-actin using anti- $\beta$-actin (1:2000 dilution) (Cell Signaling Technology, USA).

\section{Statistical analysis}

The results were represented as mean \pm SD. Values at $\mathrm{p}<0.05$ are considered significant as determined by ANOVA (one way analysis of variance) and analyses were performed using SPSS statistical package (version 17.0).

\section{Results}

In the control group, majority of cerebral cortical neurons had homogeneously stained nuclei, and the chromatins of normal nuclei were unaltered and spread equally throughout the entire nucleus (Figure 1A). However, in cells that were exposed to cadmium at 10 and $20 \mu \mathrm{mol} / \mathrm{L}$ for 12 hours, prominent nuclear morphological changes archetypal to apoptosis were observed. The cells presented condensed nuclear chromatin and fragmented nuclei. Nevertheless, in cells that were pre-treated with resveratrol, the intensity of morphological changes were considerably less.

Following cadmium exposure for 12 hours, neurotoxicity was observed as a striking decline in cell viability percentage with $20 \mu \mathrm{M}$ cadmium presenting neurotoxic effects greater than $10 \mu \mathrm{M}$ (Figure 1B). Resveratrol at various concentrations $(5,10$ and $20 \mu \mathrm{M})$ resulted in a significant $(\mathrm{p}<0.05)$ improvement in cell viability percentage. The viable neuron counts increased with increasing concentrations of resveratrol. The 20 $\mu \mathrm{M}$ concentration caused a marked raise in viability when compared to lower doses (5 and $10 \mu \mathrm{M})$.

Expression of activated caspase- 3 was comparatively less following exposure to $10 \mu \mathrm{M}$ cadmium. Incubation with resveratrol for 24 hours markedly reduced the expression of cleaved caspase- 3 in a dose-dependent manner that was in line with the results of the cell viability as in LIVE/DEAD assay and DAPI staining. Resveratrol at $20 \mu \mathrm{M}$ was more effective in downregulating the expression of activated caspase-3.

Studies have shown that cadmium disrupts $\left[\mathrm{Ca}^{2+}\right]_{\mathrm{i}}$ homeostasis leading to apoptosis and to determine $\left[\mathrm{Ca}^{2+}\right]_{\mathrm{I}}$ levels following the treatment of cerebral cortical neurons with resveratrol and/or cadmium, the cells were stained with Fluo-4 AM, an calcium indicator dye. We found that the exposure to cadmium (10 and 20 $\mathrm{mM}$ ) resulted in an concentration-dependent increase of $\left[\mathrm{Ca}^{2+}\right]_{\mathrm{i}}$ in cerebral cortical neurons (Figure 2). However, resveratrol caused a significant reduction in $\left[\mathrm{Ca}^{2+}\right]_{\mathrm{i}}$ levels.

Additionally, the combined effect of resveratrol and BAPTA-AM on cadmium-induced perturbation of $\left[\mathrm{Ca}^{2+}\right]_{\mathrm{i}}$ homeostatsis was evaluated where the cells were pre-loaded with $10 \mathrm{mM}$ BAPTA-AM for $30 \mathrm{~min}$. BAPTA -AM, an effective membrane permeable intracellular $\mathrm{Ca}^{2+}$ chelators gets trapped in the cells after cytoplasmic hydrolysis. As exemplified in Figure 2, chelating intracellular $\mathrm{Ca}^{2+}$ with BAPTA-AM prevented the elevation of $\left[\mathrm{Ca}^{2+}\right]_{i}$. Further on incubation of the neurons with 2APB, a ER calcium channel (inositol-1,4,5-trisphosphate receptor; $\mathrm{IP}_{3} \mathrm{R}$ ) blocker, the elevated levels of $\left[\mathrm{Ca}^{2+}\right]_{\mathrm{i}}$ induced by cadmium was found to be suppressed. However exposure to resveratrol without BAPTA-AM caused minor decrease in levels of $\left[\mathrm{Ca}^{2+}\right]_{\mathrm{i}}$. The combined exposure to BAPTA-AM and resveratrol was found to be more effective in suppressing the levels of raised intracellular calcium levels. Resveratrol at 20 $\mu \mathrm{M}$ was more effective in reducing the levels of $\left[\mathrm{Ca}^{+}\right]_{\mathrm{i}}$ 


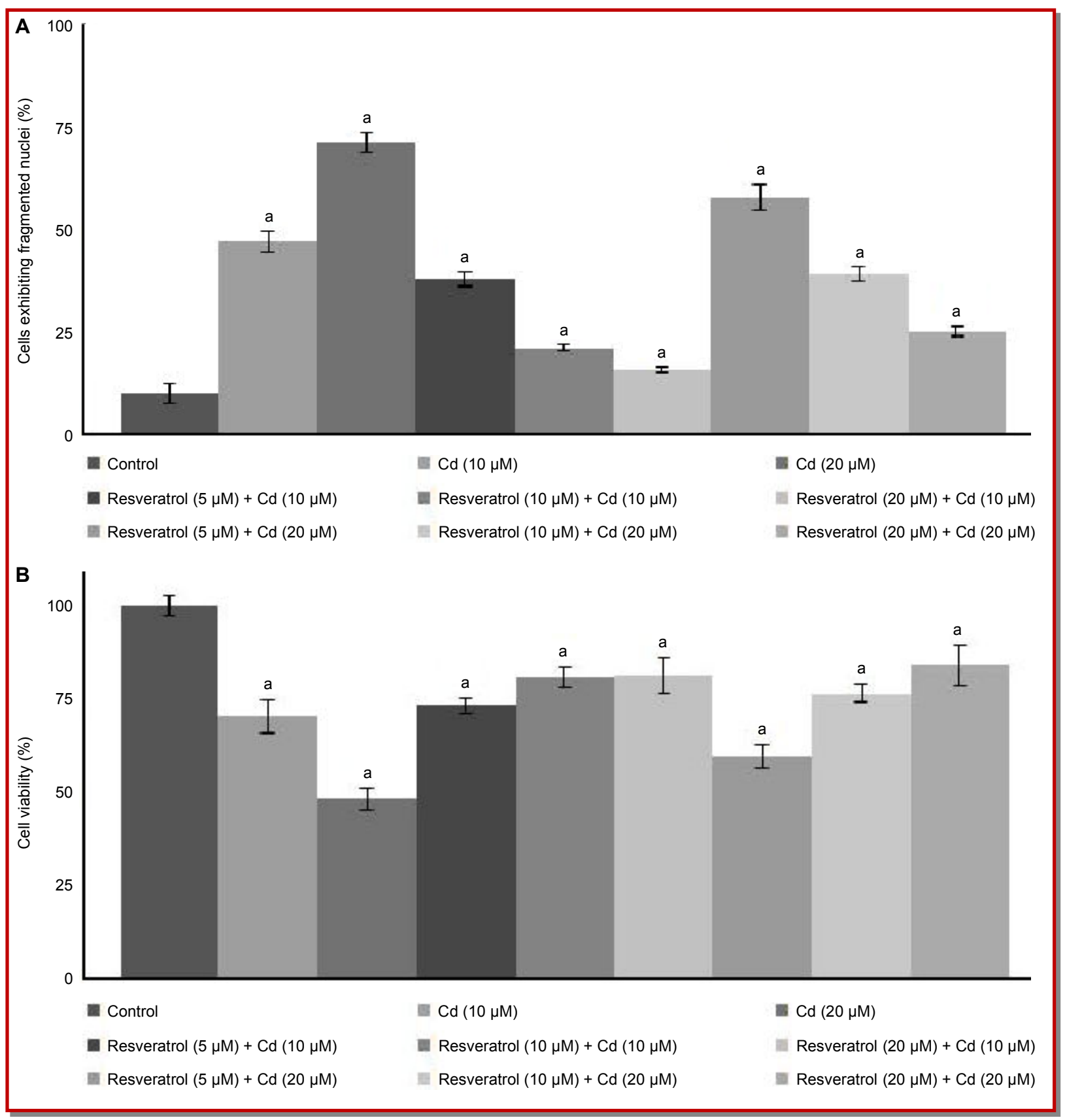

Figure 1: Resveratrol inhibits cadmium induced neuroapoptosis

Pre-treatment with resveratrol markedly reduction in morphological changes as seen by DAPI staining (A) and improved the viable cell percentage (B); Values are represented as mean $\pm \mathrm{SD} ; \mathrm{n}=6$; arepresents statistical significance at $\mathrm{p}<0.05$ compared against control as determined by one-way ANOVA

(Figure 2). While APB reduced the discharge of calcium from ER, resveratrol also caused alterations against the cadmium-induced raise in $\left[\mathrm{Ca}^{2+}\right]_{i}$ along with APB. These observations suggest that resveratrol affects cadmium-induced raised levels of intracellular calcium.

The cells that were treated with cadmium at $20 \mu \mathrm{M}$ exhibited marked increase in the levels of ROS as compared to lower dose of $10 \mu \mathrm{M}$ (Figure 3). Incubation with BAPTA-AM and/or resveratrol resulted in a multi -fold decline in ROS level. Further resveratrol and cadmium exposure in the absence of BAPTA-AM also caused a significant decrease in ROS levels, with the higher dose $(20 \mu \mathrm{M})$ of resveratrol exhibiting more potent effects than lower doses. Nevertheless, exposure to both BAPTA-AM and resveratrol presented sharp declines in ROS generation irrespective of concentration of resveratrol.

Suppression of ROS in the combined treatment was in 


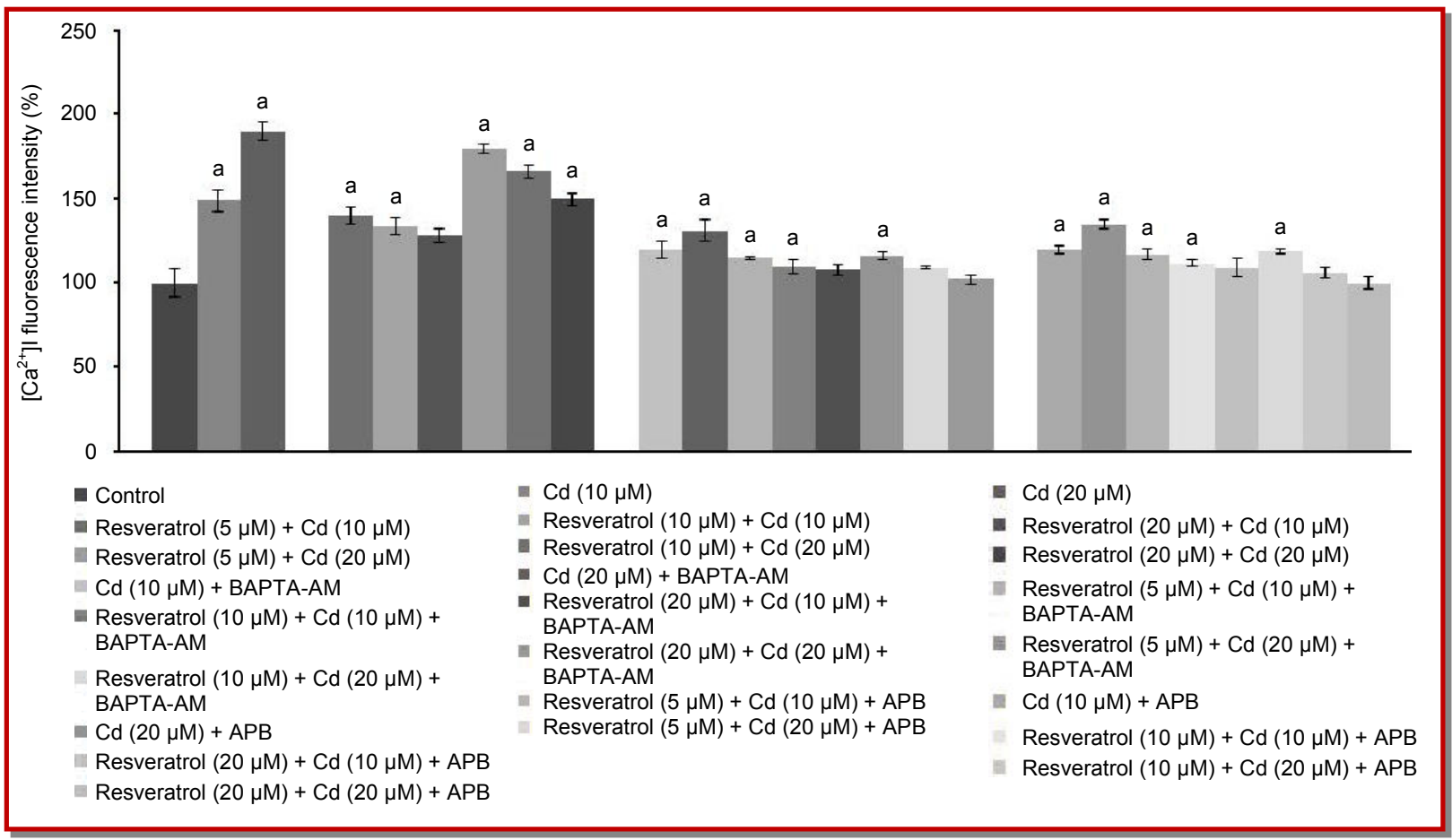

Figure 2: Resveratrol inhibits Cd-induced alterations in intracellular free calcium levels

Resveratrol with/without BAPTA-AM or AMP treatment caused significant reduction in $\left[\mathrm{Ca}^{2+}\right]_{\mathrm{i}}$ levels; Values are represented as mean $\pm \mathrm{SD}$; $=6$; arepresents statistical significance at $\mathrm{p}<0.05$ compared against control as determined by one-way ANOVA

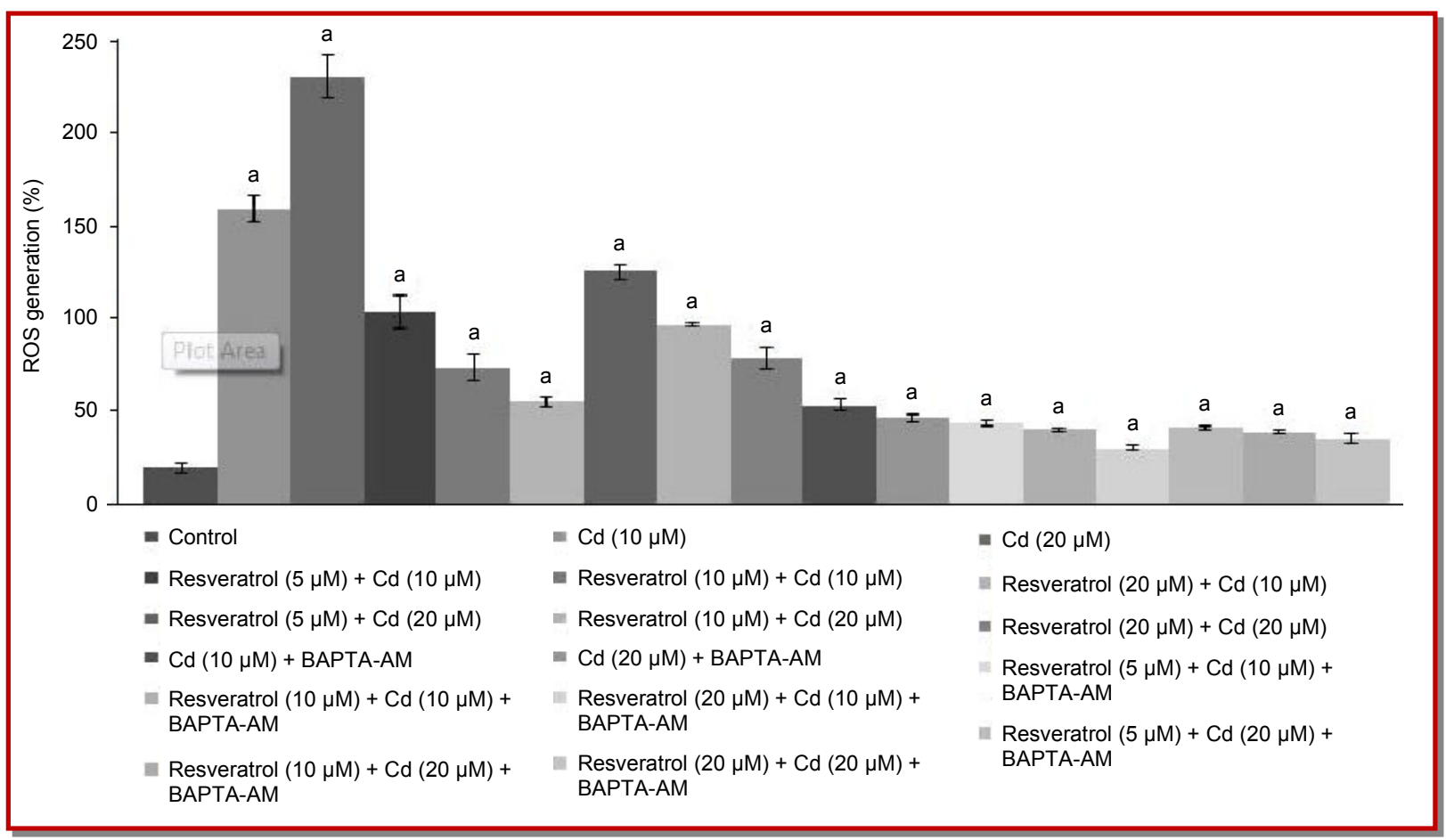

Figure 3: Resveratrol inhibits Cd-induced ROS generation

Values are represented as mean $\pm \mathrm{SD} ; \mathrm{n}=6$; arepresents statistical significance at $\mathrm{p}<0.05$ compared against control as determined by one-way ANOVA

the order: BAPTA-AM and resveratrol $(20 \mu \mathrm{M})>$ BAPTA-AM and resveratrol $(10 \mu \mathrm{M})>$ BAPTA-AM and resveratrol $(5 \mu \mathrm{M})$. The results suggest that effective decrease in ROS levels by resveratrol could be attributed to its antioxidant potency. BAPTA-AM also caused reduction in ROS level suggesting BAPTA-AM 


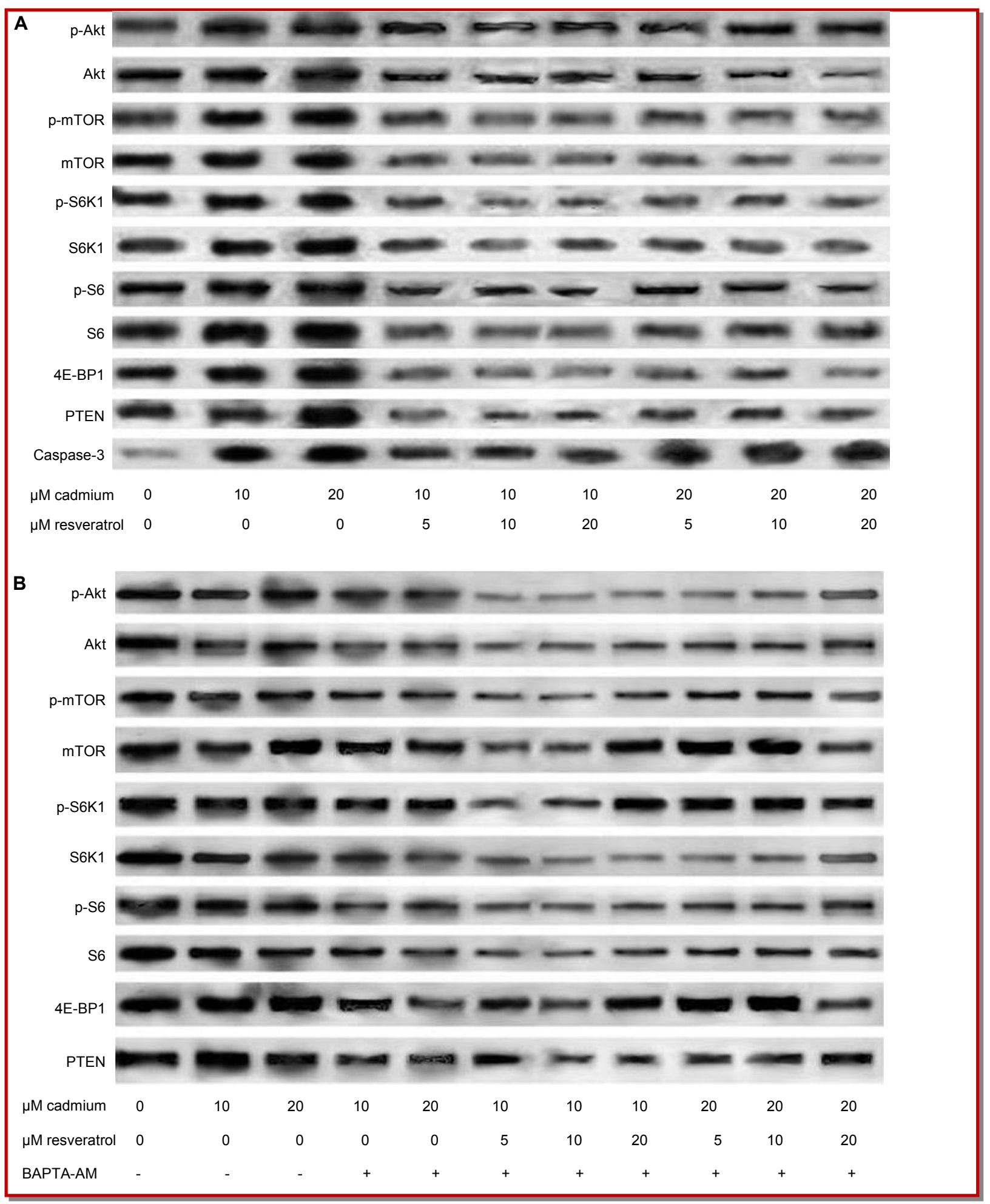

Figure 4: Resveratrol prevents cadmium induced neuronal cell death by modulating PTEN expression and Akt/ mTOR network 


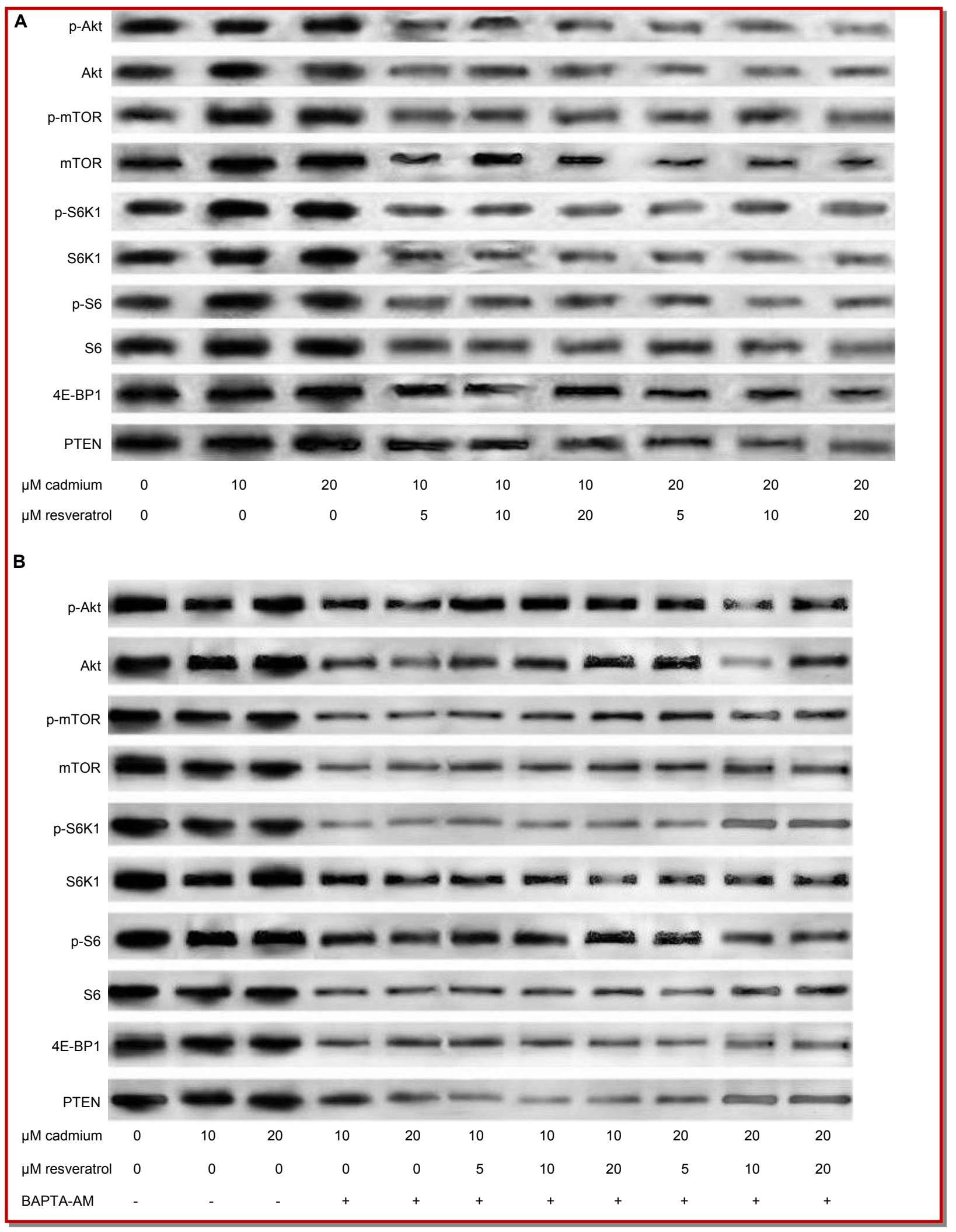

Figure 5: Resveratrol regulates the expression of MAPK pathway proteins 
blocked calcium levels that could have reduced the production of ROS.

Effect of resveratrol on cadmium induced phosphorylation of Akt, S6K and 4E-BP1 was determined. Pretreatment with varying concentrations of resveratrol markedly inhibited cadmium induced phosphorylation of Akt, S6K and 4E-BP1 in the primary cortical neurons (Figure 4A, B). At $20 \mu \mathrm{M}$, resveratrol entirely blocked the phosphorylation. Furthermore, significant downregu-lation of PTEN (phosphatase and tensin homolog deleted on chromosome 10) was observed following induction of cadmium. Resveratrol caused dosedependent up-regulation of PTEN. The results suggest that resveratrol was able to effectively inactivate Akt/ mTOR proteins and increase PTEN expression.

Cadmium-induced relative expressions of PTEN and Akt/mTOR pathway proteins under the influence of resveratrol without (a)/with BAPTA-AM (b). Resveratrol effectively modulates the expressions of the proteins.

The effects of resveratrol on the expressions of the three main members of the MAPK family: c-Jun N-terminal kinase (JNK), extracellular signal- regulated kinase (ERK) and p38 MAPK were determined. Resveratrol was found to potentially block the phosphorylation of JNK, ERK1/2, and p38 in primary neurons (Figure 5). However, no observable change in the basal expression of JNK, Erk1/2 and p38 was found. Resveratrol inhibited cadmium-induced phosphorylation of JNK and phosphorylation of c-Jun as well; c-Jun is a specific substrate of JNK (Figure 5). The effects were however dose-dependent, with $5 \mu \mathrm{M}$ of resveratrol exhibiting no obvious alterations in the expression patterns of c-Jun, JNK, ERK1/2 and p38. Maximum effects were exhibited by $20 \mu \mathrm{M}$ resveratrol. The data thus suggest that resveratrol was able to potentially inhibit cadmium induced expressions of MAPK family proteins.

Cadmium-induced alterations in the expression of MAPK pathway proteins were effectively modulated by resveratrol. The relative expressions of the proteins under the influence of resveratrol alone and with BAPTA-AM are shown in a and $b$ respectively.

\section{Discussion}

Use of chelators for effective therapy of cadmium poisoning may not hold effective for long-term exposure and also due to the side-effects associated with chelating agents (Sinicropi et al., 2010). Recent studies have shown efficacy of plant-derived compounds in cadmium poisoning. Celastrol and Epigallocatechin 3gallate have been reported to possess potential neuroprotective effects against cadmium induced neurotoxicity (Abib et al., 2011; Chen e al., 2014).
The exact mechanism through which cadmium induces neuronal apoptosis is yet to be resolved completely, while recent reports indicate the sustained activation of mitogen-activated protein kinases signalling pathways (Kim and Sharma, 2004; Kim et al., 2005) and mTOR networks (Chen et al., 2008; 2011) in cadmium induced neuroapoptosis. The present study was undertaken to evaluate whether resveratrol was able to effectively modulate cadmium induced alterations of MAPK and mTOR pathways.

Resveratrol treatment caused effective reduction in the morphological alterations in cadmium induced primary cortical neurons. The intensity of fragmented nuclei significantly reduced in resveratrol pre-treatment. Studies have shown that cadmium may trigger cell death by caspase-dependent and/or independent apoptotic mechanisms, depending on cell types (Coutant et al., 2006; Mao et al., 2007). Resveratrol was able to potentially improve the cell viability and markedly down-regulate cadmium induced robust up-regulation of caspase-3.

Cadmium disrupts $\left[\mathrm{Ca}^{2+}\right]_{\mathrm{i}}$ homeostasis, causing apoptosis in a variety of cells. In line with the previous reports (Biagioli et al., 2008; Wang et al., 2009; Xu et al., 2011), in the present study cadmium exposure caused a striking increase in the $\left[\mathrm{Ca}^{2+}\right]_{\mathrm{I}}$ levels. However, resveratrol caused a marked decrease in $\left[\mathrm{Ca}^{2+}\right]_{\mathrm{i}}$. The results were similar to the effects exerted by BAPTA$\mathrm{AM}$, that was used as a standard to chelate intracellular calcium in order to demonstrate cadmium induced elevation in $\left[\mathrm{Ca}^{2+}\right]_{i}$. Xie et al. (2010) has reported cadmium induced apoptosis as mediated by the release of $\mathrm{Ca}^{2+}$ from intracellular $\mathrm{Ca}^{2+}$ stores. Pre-treatment with 2-APB, an membrane-permeable inhibitor of $\mathrm{IP}_{3} \mathrm{R}$ (Ruiz et al., 2009), evidently reduced cadmium-induced elevation of $\left[\mathrm{Ca}^{2+}\right]_{\mathrm{i}}$ suggesting that this elevation possibly involves intracellular release from $\mathrm{Ca}^{2+}$ stores. Resveratrol exposure has also caused an obvious decrease in levels of intracellular release of $\mathrm{Ca}^{2+}$, suggesting its effect against cadmium induced release of $\mathrm{Ca}^{2+}$. As shown by Misra et al. (2003) an increase in $\mathrm{IP}_{3}$, an ligand of $\mathrm{IP}_{3} \mathrm{R}$ following exposure to cadmium suggests that cadmium could activate $\mathrm{IP}_{3} \mathrm{R}$ through increase of intracellular $\mathrm{IP}_{3}$ which then causes release of calcium from ER which is an major calcium storage compartment of the cell. Pre-treatment with an inhibitor of the calcium channel of ER $\left(\mathrm{IP}_{3} \mathrm{R}\right)$ suggests that the release of calcium from ER in stimulating apoptosis (Deniaud et al., 2008). The effect of resveratrol in reducing the levels of $\mathrm{Ca}^{2+}$ suggests that it contributes in further inhibiting the process of apoptosis by maintaining the levels of $\mathrm{Ca}^{2+}$. Decrease in the $\mathrm{Ca}^{2+}$ contributed by resveratrol exposure is found to be in line with observations of the cell viability assay and DAPI staining.

Cadmium induced neuronal toxicity is also due to 
induction of ROS leading to oxidative stress (Lopez et al., 2006; Chen et al., 2008, 2011; Thevenod et al., 2009). $\mathrm{Xu}$ et al. (2011) has demonstrated that cadmium elevated $\left[\mathrm{Ca}^{2+}\right]_{i}$ induces the ROS and obtained results of this studies also showed cadmium induced $\left[\mathrm{Ca}^{2+}\right]_{\mathrm{i}}$ elevation resulting in the induction of ROS in cerebral cortical neurons after treatment with cadmium. Resveratrol and/or BAPTA-AM markedly attenuated cadmium induced ROS, suggesting calcium-related ROS production. Elevated $\left[\mathrm{Ca}^{2+}\right]_{i}$ and ROS could lead to apoptosis. By causing a marked decrease in the levels of $\left[\mathrm{Ca}^{2+}\right]_{\mathrm{I}}$ and ROS generation, resveratrol significantly reduces neuronal apoptosis and offers protection against cadmium induced neurotoxicity.

Mitogen-activated protein kinases (MAPKs) are important signal transduction enzymes that are involved in many cellular processes including development, differentiation, proliferation and apoptosis (Hamanoue et al., 2007; Vacotto et al., 2008). Studies have demonstrated that ERK, NK and p38 MAPK, play a critical role in cadmium induced apoptosis of many cell types including neuronal cells (Xu et al., 2011; Nemmiche et al., 2012). In the present study, cadmium exposure caused an increase in the phosphorylation levels of JNK, ERK1/2, c-Jun and p38. Further following cadmium exposure the increase in p-c-Jun levels correlated with c-Jun levels. Sustained activation of JNK, Erk1/2 and/or p38 is responsible for cadmium induced apoptosis in various cells, including neuronal cells (Chuang et al., 2000; Kim et al., 2005). Resveratrol significantly down-regulated the expression levels of the phosphorylated JNK, ERK1/2, C-Jun and p38. This down-regulation in the phosphorylation status of MAPK proteins is suggestive of the reversal of MAPK pathway to normal.

mTOR has been widely recognized as a central controller of cell proliferation, growth and survival (Bjornsti and Houghton, 2004). Cadmium-induced inhibition of cell proliferation and cell viability has been reported (Lopez et al., 2003; Kim et al., 2005). Akt positively regulates $\mathrm{mTOR}$, leading to increased phosphorylation of ribosomal p70 S6 kinase (S6K1) and eukaryotic initiation factor $4 \mathrm{E}$ binding protein 1 (4EBP1), the downstream effector molecules of mTOR (Bjornsti and Houghton, 2004). In the present study, cadmium exposure caused raised phosphorylation of mTOR and Akt. As reported by Bjornsti and Houghton (2004), cadmium-induced activation of mTOR caused consequent activation of S6K1 and 4E-BP1. Resveratrol induced significant down-regulation in the phopshorylation levels of Akt and mTOR, lead to subsequent decreases in p-4E-BP1 and pS6K1. Chen et al. (2011b) reported cadmium inactivation of PTEN resulting in activation of Akt/mTOR signalling and apoptosis of neuronal cells thus implying loss of PTEN function may promote development of neurodegenerative disorders. We also witnessed cadmium exposure resulting in considerable inactivation of PTEN and the same being significantly attenuated by resveratrol. Resveratrol exposure effectively improved PTEN expression and also regulated the Akt/mTOR pathway.

The overall observations of the study indicates that cadmium-induced raised $\left[\mathrm{Ca}^{2+}\right]_{i}$ in neuronal cells subsequently induced ROS generation and activated MAPK/mTOR pathways that were potentially regulated by resveratrol. The results suggest the efficacy of resveratrol in neuroprotection. These protective effects of resveratrol may possibly be attributed to its potent antioxidant capacity.

\section{References}

Abib RT, Peres KC, Barbosa AM, Peres TV, Bernardes A, Zimmermann LM, Quincozes-Santos A, Fiedler HD, Leal RB, Farina M, Gottfried C. Epigallocatechin-3-gallate protects rat brain mitochondria against cadmium-induced damage. Food Chem Toxicol. 2011; 49: 2618-23.

Bai X, Jiang Y. Key factors in mTOR regulation. Cell Mol Life Sci. 2010; 67: 239-53.

Baxter LC, Sparks DL, Johnson SC, Lenoski B, Lopez JE, Connor DJ, Sabbagh MN. Relationship of cognitive measures and gray and white matter in Alzheimer's disease. J Alzheimers Dis. 2006; 9: 253-60.

Beyersmann D, Hechtenberg S. Cadmium, gene regulation, and cellular signalling in mammalian cells. Toxicol Appl Pharmacol. 1997; 144: 247-61.

Biagioli M, Pifferi S, Ragghianti M, Bucci S, Rizzuto R, Pinton $\mathrm{P}$. Endoplasmic reticulum stress and alteration in calcium homeostasis are involved in cadmium-induced apoptosis. Cell Calcium. 2008; 43: 184-95.

Bjornsti M, Houghton P. The TOR pathway: a target for cancer therapy. Nat Rev Cancer. 2004; 4: 335-48.

Chen L, Liu L, Huang S. Cadmium activates the mitogenactivated protein kinase (MAPK) pathway via induction of reactive oxygen species and inhibition of protein phosphatases 2A and 5. Free Radic Biol Med. 2008; 45: 103544.

Chen L, Xu B, Liu L, Luo Y, Zhou H, Chen W, Shen T, Han X, Kontos CD, Huang $S$. Cadmium induction of reactive oxygen species activates the mTOR pathway, leading to neuronal cell death. Free Radic Biol Med. 2011; 50: 624-32.

Chen L, Xu B, Liu L, Luo Y, Zhou H, Chen W, Shen T, Han X, Kontos CD, Huang S. Cadmium induction of reactive oxygen species activates the mTOR pathway, leading to neuronal cell death. Free Radic Biol Med. 2011b; 50: 624-32.

Chen S, Xu Y, Xu B Guo M, Zhang Z, Liu L, Ma H, Chen Z, Luo $Y$, Huang $S$, Chen L. CaMKII is involved in cadmium activation of MAPK and mTOR pathways leading to neuronal cell death. J Neurochem. 2011c; 119: 1108-18.

Chen S, Gu C, Xu C, Zhang J, Xu Y, Ren Q, Guo M, Huang S, Chen L. Celastrol prevents cadmium-induced neuronal cell death via targeting JNK and PTEN-Akt/mTOR network. J Neurochem._2014; 128(2): 256-66. 
Cheng A, Wang S, Yang D, Xiao R, Mattson MP. Calmodulin mediates brain-derived neurotrophic factor cell survival signaling upstream of Akt kinase in embryonic neocortical neurons. J Biol Chem. 2003; 278: 7591-99.

Chuang S. M., Wang I. C. and Yang J. L. Roles of JNK, p38 and ERK mitogen-activated protein kinases in the growth inhibition and apoptosis induced by cadmium. Carcinogenesis 2000; 21: 1423-32.

\section{Clapham DE. Calcium signaling. Cell 2007; 131: 1047-58.}

Coccini T, Barni S, Vaccarone R, Mustarelli P, Manzo L, Roda E. Pulmonary toxicity of instilled cadmium-doped silica nanoparticles during acute and subacute stages in rats. Histol Histopathol. 2013; 28: 195-209.

Coutant A, Lebeau J, Bidon-Wagner N, Levalois C, Lectard B, Chevillard S. Cadmium-induced apoptosis in lymphoblastoid cell line: Involvement of caspase-dependent and independent pathways. Biochimie. 2006; 88: 1815-22.

Cullberg KB, Foldager CB, Lind M, Richelsena B, Pedersena SB. Inhibitory effects of resveratrol on hypoxia-induced inflammation in 3T3-L1 adipocytes and macrophages. J Funct Foods. 2014; 7: 171-79.

Deniaud A, Sharaf el dein O, Maillier E, Poncet D, Kroemer G, Lemaire C, Brenner C. Endoplasmic reticulum stress induces calcium-dependent permeability transition, mitochondrial outer membrane permeabilization and apoptosis. Oncogene 2008; 27: 285-99.

Don AS, Tsang CK, Kazdoba TM, D’Arcangelo G, Young W, Zheng XF. Targeting mTOR as a novel therapeutic strategy for traumatic CNS injuries. Drug Discov Today. 2012; 17: 861-68.

Figueiredo-Pereira ME, Yakushin S, Cohen G. Disruption of the intracellular sulfhydryl homeostasis by cadmium-induced oxidative stress leads to protein thiolation and ubiquitination in neuronal cells. J Biol Chem. 1998; 273: 12703-09.

Fremont L. Biological effects of resveratrol. Life Sci. 2000; 66: 663-73.

Fulda S. Resveratrol and derivatives for the prevention and treatment of cancer. Drug Discovery Today 2010; 15(17-18): 757-65.

Green KN, Peers C. Divergent pathways account for two distinct effects of amyloid beta peptides on exocytosis and $\mathrm{Ca}\left({ }^{2+}\right)$ currents: involvement of ROS and NF-kappaB. J Neurochem. 2002; 81: 1043-51.

Gulati P, Gaspers LD, Dann SG, Joaquin M, Nobukuni T, Natt F, Kozma SC, Thomas AP, Thomas G. Amino acids activate mTOR complex 1 via Ca2+ /CaM signaling to hVps34. Cell Metab. 2008; 7: 456-65.

Hamanoue M, Sato K, Takamatsu K. Inhibition of p38 mitogen -activated protein kinase-induced apoptosis in cultured mature oligodendrocytes using SB202190 and SB203580. Neurochem Int. 2007; 51: 16-24.

Jiang LF, Yao TM, Zhu ZL, Wang C, Ji LN. Impacts of Cd(II) on the conformation and self-aggregation of Alzheimer's tau fragment corresponding to the third repeat of microtubulebinding domain. Biochim Biophys Acta. 2007; 1774: 1414-21

Kim J, Sharma RP. Calcium-mediated activation of c-Jun NH2- terminal kinase (JNK) and apoptosis in response to cadmium in murine macrophages. Toxicol Sci. 2004; 81: 51827.

Kim S, Moon C, Eun S, Ryu P, Jo S. Identification of ASK1, MKK4, JNK, c-Jun, and caspase-3 as a signaling cascade involved in cadmium-induced neuronal cell apoptosis. Biochem Biophys Res Commun. 2005; 328: 326-34.

Lemarie A, Lagadic-Gossmann D, Morzadec C, Allain N, Fardel O, Vernhet L. Cadmium induces caspase-independent apoptosis in liver Hep3B cells: Role for calcium in signaling oxidative stress-related impairment of mitochondria and relocation of endonuclease $G$ and apoptosisinducing factor. Free Radic Biol Med. 2004; 36: 1517-31.

Lephart ED, Sommerfeldt JM, Andrus MB. Resveratrol: Influences on gene expression in human skin. J Funct Foods. 2014; 10:377-84.

Lin CY, Hsiao WC, Wright DE, Hsu CL, Lo YC, Hsu GSW, Kao $\mathrm{CF}$. Resveratrol activates the histone H2B ubiquitin ligase, RNF20, in MD A-MB-231 breast cancer cells. J Funct Foods. 2013; 5: 790-800.

Liu Y, Templeton DM. Initiation of caspase-independent death in mouse mesangial cells by $\mathrm{Cd}^{2+}$ : Involvement of p38 kinase and CaMK-II. J Cell Physiol. 2008; 217: 307-18.

Lohmann RD, Beyersmann D. Cadmium and zinc mediated changes of the $\mathrm{Ca} 2+$-dependent endonuclease in apoptosis. Biochem Biophys Res Commun. 1993; 190: 1097-1103.

Lopez E, Figueroa S, Oset-Gasque MJ, Gonzalez MP. Apoptosis and necrosis: two distinct events induced by cadmium in cortical neurons in culture. Br J Pharmacol. 2003; 138: 90111.

Lopez E, Arce C, Oset-Gasque MJ, Canadas S, Gonzalez MP. Cadmium induces reactive oxygenspecies generation and lipid peroxidation in cortical neurons in culture. Free Radic Biol Med. 2006; 40: 940-51.

Lu HF, Sue CC, Yu CS, Chen SC, Chen GW, Chung JG. Diallyl disulfide (DADS) induced apoptosis undergo caspase-3 activity in human bladder cancer T24 cells. Food Chem Toxicol. 2004; 42: 1543-52.

Lukawski K, Nieradko B, Sieklucka-Dziuba M. Effects of cadmium on memory processes in mice exposed to transient cerebral oligemia. Neurotoxicol Teratol. 2005; 27: 575-84.

Maehama T, Dixon JE. The tumor suppressor, PTEN/MMAC1, dephosphorylates the lipid second messenger, phosphatidylinositol 3,4,5-trisphosphate. J Biol Chem. 1998; 273: 13375 $-78$.

Mao WP, Ye JL, Guan ZB, Zhao JM, Zhang C, Zhang NN, Jiang $\mathrm{P}$, Tian T. Cadmium induces apoptosis in human embryonic kidney (HEK) 293 cells by caspase-dependent and -independent pathways acting on mitochondria. Toxicol in Vitro 2007; 21: 343-54.

Mendez-Armenta M, Rios C. Cadmium neurotoxicity. Environ Toxicol Pharmacol. 2007; 23: 350-58.

Misra UK, Gawdi G, Akabani G, Pizzo SV. Cadmium-induced DNA synthesis and cell proliferation in macrophages: The role of intracellular calcium and signal transduction mechanisms. Cell Signal 2002; 14: 327-40. 
Misra UK, Gawdi G, Pizzo SV. Induction of mitogenic signalling in the 1LN prostate cell line on exposure to submicromolar concentrations of cadmium ${ }^{+}$. Cell Signal 2003; 15: 1059-70.

Napolitano JR, Liu MJ, Bao S, Crawford M, Nana-Sinkam P, Cormet-Boyaka E, Knoell DL. Cadmium-mediated toxicity of lung epithelia is enhanced through NF-kappaB mediated transcriptional activation of the human zinc transporter ZIP8. Am J Physiol Lung Cell Mol Physiol. 2012; 302: L90918.

Neher E, Sakaba T. Multiple roles of calcium ions in the regulation of neurotransmitter release. Neuron 2008; 59: 86172 .

Nemmiche S, Chabane-Sari D, Kadri M, Guiraud P. Cadmiuminduced apoptosis in the BJAB human $\mathrm{B}$ cell line: involvement of PKC/ERK1/2/JNK signaling pathways in HO-1 expression. Toxicology 2012; 300: 103-111.

Nishimura Y, Yamaguchi JY, Kanada A, Horimoto K, Kanemaru K, Satoh M, Oyama Y. Increase in intracellular $\mathrm{Cd} 2+$ concentration of rat cerebellar granule neurons incubated with cadmium chloride: Cadmium cytotoxicity under external $\mathrm{Ca}^{2+}$-free condition. Toxicol in Vitro 2006; 20: 211-16.

Okuda B, Iwamoto Y, Tachibana H, Sugita M. Parkinsonism after acute cadmium poisoning. Clin Neurol Neurosurg. 1997; 99: 263-65.

Oliveira H, Lopes T, Almeida T, Pereira Mde L, Santos C. Cadmium induced genetic instability in mice testis. Hum Exp Toxicol. 2012; 31: 1228-36.

Panayi AE, Spyrou NM, Iversen BS, White MA, Part P. Determination of cadmium and zinc in Alzheimer's brain tissue using inductively coupled plasma mass spectrometry. J Neurol Sci. 2002; 195: 1-10

Pihl RO, Parkes M. Hair element content in learning disabled children. Science 1977; 198: 204-06.

Polak P, Hall MN. mTOR and the control of whole body metabolism. Curr Opin Cell Biol. 2009; 21: 209-18.

Prabu SM, Shagirtha K, Renugadevi J. Naringenin in combination with vitamins $C$ and $E$ potentially protects oxidative stress-mediated hepatic injury in cadmium-intoxicated rats. J Nutr Sci Vitaminol (Tokyo). 2011; 57: 177-85.

Ravikumar B, Vacher C, Berger Z, Davies JE, Luo S, Oroz LG, Scaravilli F, Easton DF, Duden R, O'Kane CJ, Rubinsztein DC. Inhibition of mTOR induces autophagy and reduces toxicity of polyglutamine expansions in fly and mouse models of Huntington disease. Nat Genet. 2004; 36: 585-95.

Ruiz A, Matute C, Alberdi E. Endoplasmic reticulum $\mathrm{Ca}^{2+}$ Release through ryanodine and IP3 receptors contributes to neuronal excitotoxicity. Cell Calcium 2009; 46: 273-81.

Sinicropi MS, Amantea D, Caruso A, Saturnino C. Chemical and biological properties of toxic metals and use of chelating agents for the pharmacological treatment of metal poisoning. Arch Toxicol. 2010; 84: 501-20.

Son YO, Lee JC, Hitron JA, Pan J, Zhang Z, Shi X. Cadmium induces intracellular $\mathrm{Ca}^{2+}$ - and $\mathrm{H}_{2} \mathrm{O}_{2}$-dependent apoptosis through JNK- and p53-mediated pathways in skin epidermal cell line. Toxicol Sci. 2010; 113: 127-37.

Sovak M. Grape extract, resveratrol, and its analogs: A review. J Med Food 2001; 4: 93-105.

Stohs SJ, Bagchi D. Oxidative mechanisms in the toxicity of metal ions. Free Radic Biol Med. 1995; 18: 321-36.

Surmeier DJ, Guzman JN, Sanchez-Padilla J. Calcium, cellular aging, and selective neuronal vulnerability in Parkinson's disease. Cell Calcium 2010; 47: 175-82.

Swiech L, Perycz M, Malik A, Jaworski J. Role of mTOR in physiology and pathology of the nervous system. Biochim Biophys Acta. 2008; 1784: 116-32.

Thevenod F. Cadmium and cellular signaling cascades: to be or not to be? Toxicol Appl Pharmacol. 2009; 238: 221-39.

Vacotto M, Coso O, Fiszer de Plazas S. Programmed cell death and differential JNK, p38 and ERK response in a prenatal acute hypoxic hypoxia model. Neurochem Int. 2008; 52: 85763.

Wang S, Tang M, Pei B, Xiao X, Wang J, Hang H, Wu L. Cadmium-induced germline apoptosis in Caenorhabditis elegans: The roles of HUS1, p53, and MAPK signalling pathways. Toxicol Sci. 2008; 102: 345-51.

Wang L, Cao J, Chen D, Liu X, Lu H, Liu Z. Role of oxidative stress, apoptosis, and intracellular homeostasis in primary cultures of rat proximal tubular cells exposed to cadmium. Biol Trace Elem Res. 2009; 127: 53-68.

Wright RO, Amarasiriwardena C, Woolf AD, Jim R, Bellinger DC. Neuropsychological correlates of hair arsenic, manganese, and cadmium levels in school-age children residing near a hazardous waste site. Neurotoxicology 2006; 27: 21016

Xie Z, Zhang Y, Li A, Li P, Ji W, Huang D. Cd-induced apoptosis was mediated by the release of $\mathrm{Ca} 2+$ from intracellular Ca storage. Toxicol Lett. 2010; 192: 115-18

Xu B, Chen S, Luo Y, Chen Z, Liu L, Zhou H, Chen W, Shen T, Han X, Chen L, Huang S. Calcium signaling is involved in cadmium-induced neuronal apoptosis via induction of reactive oxygen species and activation of $\mathrm{MAPK} / \mathrm{mTOR}$ network. PLoS One 2011; 6: e19052.

Yan Y, Bian JC, Zhong LX, Zhang Y, Sun Y, Liu ZP. Oxidative stress and apoptotic changes of rat cerebral cortical neurons exposed to cadmium in vitro. Biomed Environ Sci. 2012; 25: 172-81.

Yang CS, Tzou BC, Liu YP, Tsai MJ, Shyue SK, Tzeng SF. Inhibition of cadmium-induced oxidative injury in rat primary astrocytes by the addition of antioxidants and the reduction of intracellular calcium. J Cell Biochem. 2008; 103: 825-34. 